\title{
CASE REPORT: REACTIVE PERFORATING COLLAGENOSIS IN RHEUMATOID ARTHRITIS PATIENT AFTER USE OF CERTOLIZUMAB PEGOL
}

Elizandra Tomazela Laurenti Polito ${ }^{1}$, Bruna Scardini Salaroli ${ }^{1}$, Luiz Fellipe Favoreto Genelhu ${ }^{1}$, Thays Zanon Casagrande ${ }^{1}$, Ana Paula Espindula Gianordoli², Leticia Resende Brandao ${ }^{1, \star}$

1.Hospital Estadual Dorio Silva, Serra (ES), Brazil; 2.Universidade Federal do Espírito Santo, Vitória (ES), Brazil.

*Corresponding author: eliz.polito@gmail.com

\section{BACKGROUND}

Skin manifestations are difficult to diagnose in patients with rheumatic diseases. We describe a case of a patient with rheumatoid arthritis (RA) presenting a rare picture of reactive perforating collagenosis (RPC), after the use of certolizumab pegol.

\section{CASE REPORT}

A 53-year-old female with RA (2013), positive anti-CCP and rheumatoid factor test. She had skin side effects secondary to various treatments, eczema aspect and associated pruritus (methotrexate, leflunomide). In 2019 evolved to palmoplantar psoriasis after the fifth month of adalimumab. Adalimumab was suspended and certolizumab pegol was started in February 2020. After induction dose, the patient returned for the follow-up presenting pustular skin lesions in buttocks, lower limbs, armpits, breasts and scalp. Lesions evolved with ulceration, necrotic center and elevated edges, very painful, similar to gangrenous pyoderma (Figure 1). No improvement with antibiotics. We suspended certolizumab pegol and started corticosteroid $60 \mathrm{mg} /$ day with little improvement (Figure 2). Serologies for HIV, Hep B, Hep C, VDRL negative, ANCA, lupus anticoagulant negative, normal PCR, ESR 60, normal blood count, normal renal function and hepatica, negative tuberculin skin test. In December 2020 , chest, abdomen and pelvis CT was performed without suspicious lesions. Skin and subcutaneous biopsy of the lateral side of the thigh was consistent with RPC, with perforating dermatitis with epidermal acanthosis and necrobiosis of the superficial dermis associated with epithelioid granulomas in palisade and superficial and deep lymphoplasmacytic inflammatory infiltrate. The research for acid alcohol resistant bacillus and fungus were negative. In this same period, prescribed sulfamethoxazole and trimethoprim and weaning of the corticosteroid was started. In January 2021, leflunomide was reintroduced. The patient has no new lesion since April 2021 and continues in progressive improvement with scar injuries (Figures 3 and 4 ) and ESR normalization.
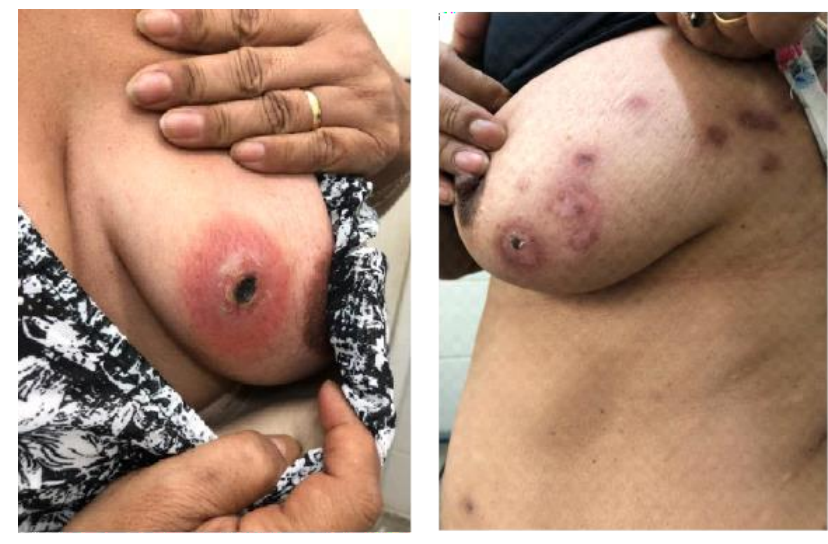

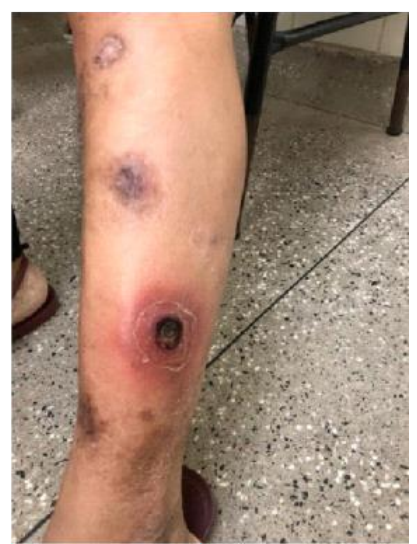

Figure 1. Photos of May 2020. 

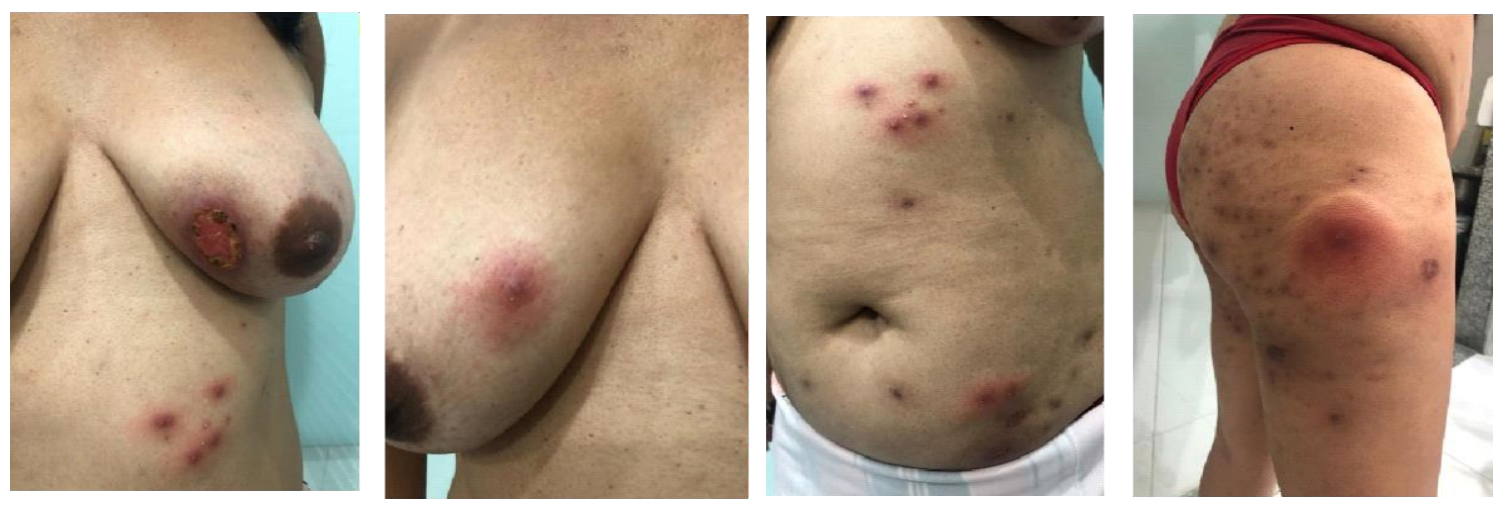

Figure 2. Photos of December 2020.
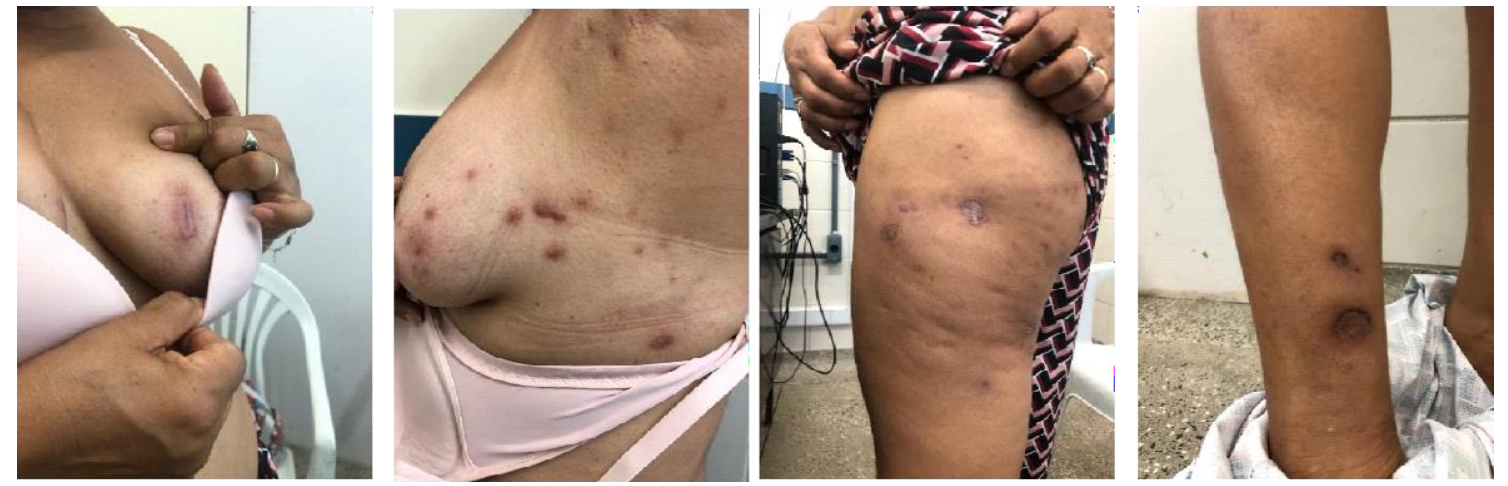

Figure 3. Photos of February 2021.
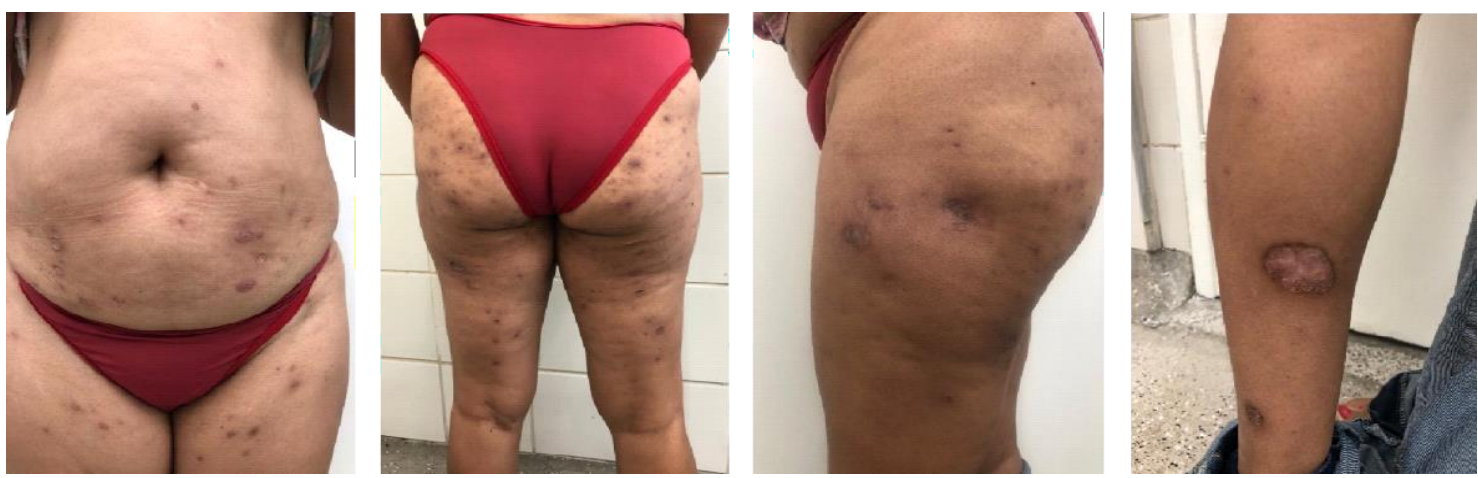

Figure 4. Photos of May 2021.

\section{CONCLUSION}

Reactive perforating collagenosis is characterized by trans epidermal elimination of collagen. It may be primary, possible autosomal recessive inheritance, or secondary, associated with systemic diseases, especially diabetes and chronic renal insufficiency. In cases where there is an underlying disease, its control can lead to improvement. In a review of the literature, we did not find an association of RPC with RA or with the use of anti-TNF, especially certolizumab. In this patient, the suspension of certolizumab pegol, as well as the reintroduction of leflunomide and corticosteroids in low dose was effective for the improvement of the condition.

\section{KEYWORDS}

Reactive perforating collagenosis, Rheumatoid arthritis, Anti-TNF, Certolizumab pegol. 